\title{
Usefulness of left ventricular peak filling rate measurement by cardiac MR imaging in heart transplant recipients with cardiac allograft vasculopathy
}

Haruhiko Machida*, Shinichi Nunoda, Kiyotaka Okajima, Kazunobu Shitakura, Akihiko Sekikawa, Kuniaki Suwa, Tomoko Kikuchi, Shun Nakajima, Miwa Hattammaru, Reiko Hozo, Tetsuya Mitsuhashi, Yutaka Kubo, Kuniaki Otsuka, Masami Hirata, Shinya Kojima, Ai Masukawa, Satoru Morita, Kazufumi Suzuki and Eiko Ueno

Address: Tokyo Women's Medical University Medical Center East, Tokyo, Japan

* Corresponding author

from I3th Annual SCMR Scientific Sessions

Phoenix, AZ, USA. 2I-24 January 2010

Published: 21 January 2010

Journal of Cardiovascular Magnetic Resonance 2010, I2(Suppl I):O98 doi:I0.I I86/I532-429X-I2-SI-O98

This abstract is available from: http://jcmr-online.com/content/I2/SI/O98

(c) 2010 Machida et al; licensee BioMed Central Ltd.

\section{Introduction}

Cardiac allograft vasculopathy (CAV), a major late complication for heart transplant recipients, is characterized as a diffuse intimal hyperplasia of the coronary artery. Invasive coronary angiography and coronary flow reserve (CFR) measurement are often performed, but have some limitations for CAV screening of asymptomatic recipients. This vasculopathy usually accelerates left ventricular (LV) diastolic dysfunction before systolic dysfunction. It has not been fully investigated which is more useful for detecting CAV, cardiac MR measurement of peak filling rate (PFR) as an index of LV diastolic function or invasive CFR measurement.

\section{Purpose}

We investigated the feasibility of noninvasive PFR measurement by MR for detecting CAV over invasive CFR measurement in recipients.

\section{Methods}

Between June 2006 and June 2009, 52 asymptomatic recipients (35 men, 17 women, aged $35.1 \pm 15.4$ years) underwent both cardiac MR and intravascular ultrasound (IVUS) $8.4 \pm 4.5$ years after heart transplantation. We measured LV PFR normalized to end-diastolic volume (EDV) and ejection fraction (EF) by steady-state free precession cine MR imaging. We measured coronary flow reserve as ratio of maximal hyperemic to baseline coronary flow velocity by Doppler guidewire in 47 (90\%) of these 52 recipients. According to Stanford classification based on intimal wall morphology assessed by IVUS, we classified recipients of grade 0-2 as negative and grade 3-4 as positive for CAV and compared the PFR, EF, and CFR values between the 2 groups using unpaired t-test. We calculated receiver operating characteristic (ROC) curve in the relationship between PFR value and CAV and determined PFR cut-off value. Likewise, we classified recipients of low and high PFR based on the cut-off value and com-

Table I:

\begin{tabular}{llll}
\hline & CAV negative & CAV positive & P value \\
\hline CFR & $3.34 \pm 0.87$ & $3.06 \pm 1.17$ & 0.340 \\
\hline EF (\%) & $59.8 \pm 7.8$ & $57.7 \pm 8.5$ & 0.359 \\
\hline PFR (EDV/sec) & $4.44 \pm 0.87$ & $3.68 \pm 0.89$ & 0.003
\end{tabular}


Table 2:

\begin{tabular}{llll}
\hline & High PFR & Low PFR & P value \\
\hline CFR & $3.46 \pm 0.97$ & $2.73 \pm 0.95$ & 0.017 \\
\hline EF (\%) & $60.9 \pm 7.5$ & $54.3 \pm 7.7$ & 0.004 \\
\hline
\end{tabular}

pared the EF and CFR values. $P<0.05$ was considered statistically significant.

\section{Results}

We classified 24 patients (46\%) positive and 28 (54\%) negative for CAV. Although there was no significant difference in the EF and CFR values, the PFR value was significantly lower in the positive than negative group (Table 1 ). Area under the ROC curve was 0.750 . When PFR cut-off value was 3.50 , CAV sensitivity was $51.6 \%$ and specificity, $83.5 \%$. Using this cut-off value, EF and CFR values were significantly lower in the low than high PFR group (Table 2).

\section{Conclusion}

The impairment of LV diastolic function may precede coronary microvasular and LV systolic dysfunction. For asymptomatic heart transplant recipients, PFR measurement with cardiac MR allows the most sensitive detection of CAV noninvasively.
Publish with Bio Med Central and every scientist can read your work free of charge

"BioMed Central will be the most significant development for disseminating the results of biomedical research in our lifetime. " Sir Paul Nurse, Cancer Research UK

Your research papers will be:

- available free of charge to the entire biomedical community

- peer reviewed and published immediately upon acceptance

- cited in PubMed and archived on PubMed Central

- yours - you keep the copyright

Submit your manuscript here:

http://www.biomedcentral.com/info/publishing_adv.asp 